\section{Unpacking Layers of Space-Time Complexity in Land-Use Dynamics. A Case Study from the Olive Agrosystems of Sicily (Italy)}

\author{
Gl_Forum 2021, Issue 2 \\ Page: $108-121$ \\ Full Paper \\ Corresponding Author: \\ vincenza.ferrara@arkeologi.uu.se \\ DOI: 10.1553/giscience2021_02_s108
}

\author{
Vincenza Ferrara ${ }^{1,2}$ and Anders Wästfelt2 \\ Uppsala University, Sweden \\ 2Stockholm University, Sweden
}

\begin{abstract}
The biocultural heritage of historical landscapes is an expression of intertwined ecological and socio-cultural dynamics at different temporal and spatial scales. Such a legacy is what confers high nature value on agricultural systems worldwide. Today there is an urgent need to develop approaches that may allow a more integrated study of biocultural heritage in order to better direct future endeavours for the sustainable management on such agricultural systems. Here, a methodological approach to unpack space-time complexity in the land-use dynamics of historic and current-day agrosystems is presented, based on the use of contextual and spatial-relational segmentation techniques within the research framework of historical ecology.

With reference to work done in a case study area in Sicily, the authors first extract geographic contextual configurations and develop a spatial-relational ontology for their semantic interpretation, before using these spatial objects as temporal proxies to disentangle the spatial and temporal dynamics of land use. The result is a cross-disciplinary approach in which perspectives from historical ecology can be used to achieve a deeper understanding of evidence extracted from remotely sensed images. At the same time, advanced spatial analysis techniques may provide a further interpretative tool for scientific inquiry into biocultural heritage.
\end{abstract}

\title{
Keywords:
}

historical ecology, contextual analysis, relational ontology, olive

\section{Introduction}

In the face of massive environmental, societal and cultural changes, research on historic agricultural landscapes and their biocultural heritage is crucial. Intercropping and agroforestry systems worldwide are all part of high nature value landscapes maintained through customary practices of management, protection and living heritage. These complex systems result from entwined dynamics occurring at different temporal and spatial scales. Thus cross-disciplinary approaches may allow a more integrated study of the systems' past, to direct future endeavours for their sustainable management (Manzano et al., 2020). 
Here, a methodological approach to unpack space-time complexity in the land-use dynamics of historic agrosystems is presented. The approach is step-wise: (a) application of contextual and spatial-relational analysis to segment different land-use arrangements into spatial objects; (b) development of a spatial-relational ontology allowing a deeper semantic interpretation of the different spatial arrangements in terms of land-use strategies and human intentions; (c) the use of these spatial objects as temporal proxies to extract timescales of use dynamics.

With roots in archaeology and anthropology, historical ecology is a cross-disciplinary approach fostering the in-depth study of human-environmental heterarchical interactions happening at multiple spatial and temporal scales (Ray and Fernández-Götz, 2019). The use of remote sensing to analyse past human-nature systems (Pricope et al., 2019) and the application of object-based image analysis with geographic components (Hay and Castilla, 2008; Blaschke et al., 2014; Lang et al., 2019) in archaeology and related disciplines (Davis, 2019; Agapiou, 2020; Luo et al., 2019; Tapete, 2018) have focused so far on the semi-automatic digitalization of heritage maps (Gobbi et al., 2019), the extraction of information from remotely sensed data, mainly for feature detection (Sevara et al., 2016, Lasaponara and Masini, 2014), and the identification of surface and sub-surface remains (Lambers and Traviglia, 2016; Traviglia and Torsello, 2017). In many applications, a pre-defined ontology (Schuurman, 2006) of the imageobjects detected is used as a tool to model real-world objects (Blaschke et al., 2014). In archaeology, in the course of the development of the GEOBIA ontology (Magnini and Bettineschi, 2019; Lombardo et al., 2020), the need to consider the spatial context and the temporal dimensions has been progressively highlighted (Calafiore et al., 2017; Sevara et al., 2016; Mathian and Sanders, 2015), accompanied by a call for attention to be paid to systems of related entities in the landscape, not single separate semantic objects (Traviglia and Torsello, 2017).

Thanks to its unique position in the Mediterranean, the island of Sicily has been a cross-roads of cultures for millennia, representing a special case of long-term human-nature interrelationships and presenting high biological diversity of endemic species. The persistence of certain biocultural refugia in the landscape (Barthel et al., 2013) can be seen as the nondiscursive result of a long-term cultural negotiation between humans and nature. In previous work (Ferrara et al., 2019), the authors demonstrated that the different spatial patterns resulting from the cultivation of Olea Europea var. sativa in the island (the olive tree, well known for its longevity) are related to a variety of land-use practices which differ over time. As such (spatial) biocultural continuities in the landscape are the expression of human-nature dynamics over time, contextual and spatial-relational analysis (Gurney and Townshend, 1983; Ahlqvist et al., 2012; Malmberg et al., 2014) can be applied to extract useful information. When integrated with other sources of evidence (i.e. from fieldwork), this information may allow a temporal categorization of the spatial patterns extracted. Such historical disentangling of landscape features may provide useful insights into centuries or even millennia of human-nature processes, allowing a better understanding of the foundational ecological and social dynamics underpinning biocultural heritage and present-day biodiversity (Crumley, 2019; Wästfelt, 2021).

The work presented here aims to contribute in this direction. The authors first describe in detail the methodology developed and the data used, with reference to work carried out in a case study area from 2016 onwards, and then present the results obtained. The results are 
discussed, limitations pointed out, and the potential contributions of the approach for other disciplinary investigations in landscape and land-use studies are highlighted.

\section{Study area and Methods}

\subsection{Study area}

The study site, which had already been the subject of previous work (Ferrara et al., 2019), is located in the municipality of Villarosa, in central Sicily (Italy). The study area, a mosaic of olive orchards that are apparently homogeneous in terms of land cover and land use, covers an area $1,943 \mathrm{~km}^{2}$ and rises to approximately 550 metres AMSL (Figure 1).

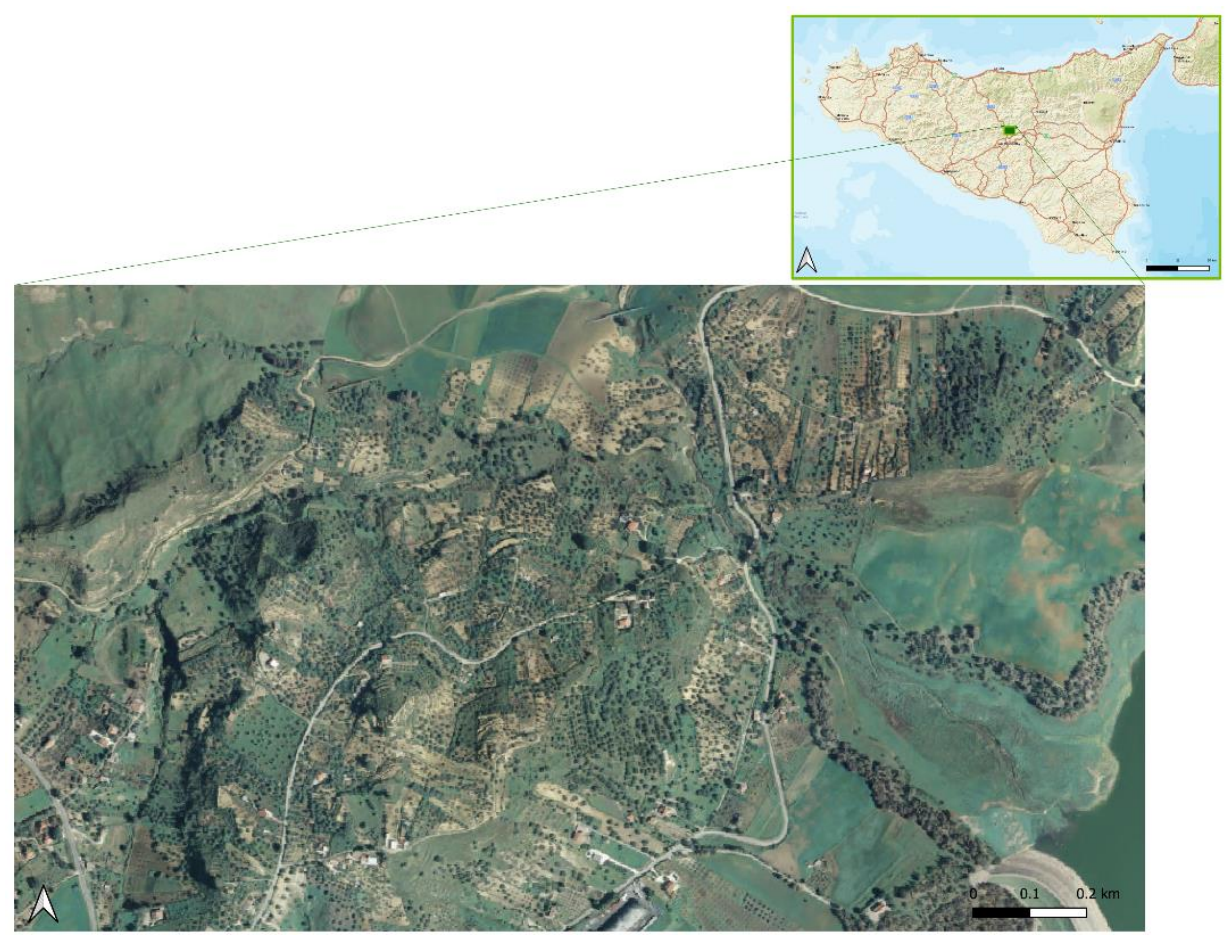

Figure 1: RGB orthophoto of the study area, Urbanistic and Environmental Department of the Sicilian Region, 2007, resolution $0.25 \mathrm{~m}$.

\subsection{Methods}

The approach presented here is based on three steps:

a. application of contextual and spatial-relational analysis, with the aim of segmenting into separate objects the different spatial cultivation arrangements of the olive trees present in the study area; 
b. development of a spatial-relational ontology allowing a deeper semantic interpretation and classification of the different spatial arrangements into classes, in terms of land-use strategies and human intentions;

c. use of these spatial classes as temporal proxies from which to semantically extract temporal classes (as expressions of different time scales in the land-use dynamics).

\section{Contextual and spatial-relational analysis}

As a first step, a contextual and spatial-relational analysis was performed on an RGB orthophoto of the study area from 2007. With a spatial resolution of 0.25 metres, the image comes from the most recent freely available dataset provided by the Urbanistic and Environmental Department of the Sicilian Region.

The orthophoto was segmented and classified using a 3-step, semi-automated classification method developed by Malmberg et al. (2014) (Figure 2). This method uses both spectral and contextual relational criteria for the classification, allowing the user to decide a priori the number of classes to extract and the segmentation radius. In this case, the authors chose to use a segmentation radius of 55 pixels and to classify the image into 11 classes. The three steps of Malmberg et al.'s (2014) method are:

1. Initial classification using $\mathrm{k}$-means clustering;

2. The calculation of the largest nearest-neighbour distance between each pixel and each pixel belonging to each class from step 1;

3. A second classification (again using k-means), performed on the basis of the largest nearestneighbour distances calculated in step 2 .

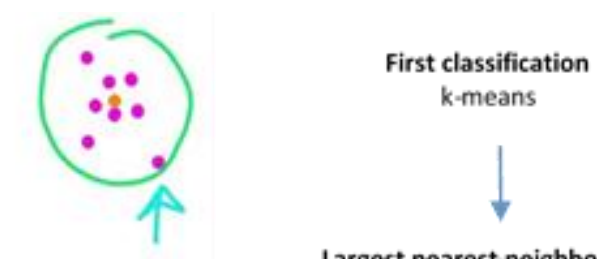

Largest nearest-neighbour distance

Each pixel \&-- > each pixel from each class extracted above

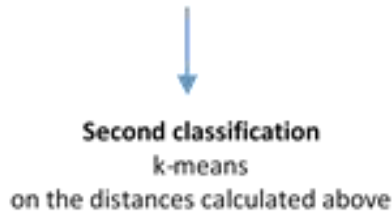

Possibility of separating

pixels of the same spectral class

according to their different spatial context

Figure 2: Workflow of the method developed by Malmberg et al. (2014) for semi-automatic classification of image information. 
After these steps had been executed, a new composite image was obtained (Figure 3c). The use of the largest nearest-neighbour distance as a geometric criterion for the second classification allows the separation of pixels originally belonging to the same object and their classification into two or more different objects, depending on similarities identified in their spatial contexts (Figure 3b and 3d). From the visual interpretation of this processed image and its comparison with the initial raw orthophoto (Figure 3a), it emerged that the semi-automated classification method had been able to identify and group into objects a number of homogeneous areas. The local configurations of these areas correspond to specific spatial arrangements of their main vegetation features (olive trees) in relationship with other relevant features (i.e. vegetation, topographic and human-made elements) (Figure 3d). In other words, in the processed image, pixels were grouped into objects that should not be interpreted as representing the spectral reflectance of different items on the ground (vegetation, concrete, water, etc.), but rather as their geographical contextual configuration. The authors believe that this opens up a higher level of semantic abstraction in assigning meanings to these spatial objects.

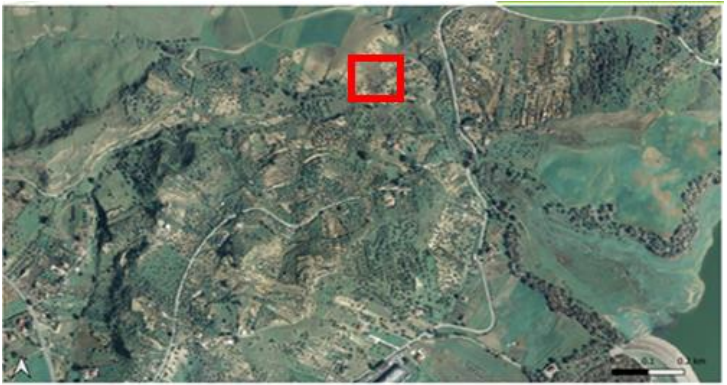

Figure 3a: Initial raw RGB orthophoto.

The red square indicates a section of the fieldwork area, detailed in Figures $3 b$ and $3 d$.

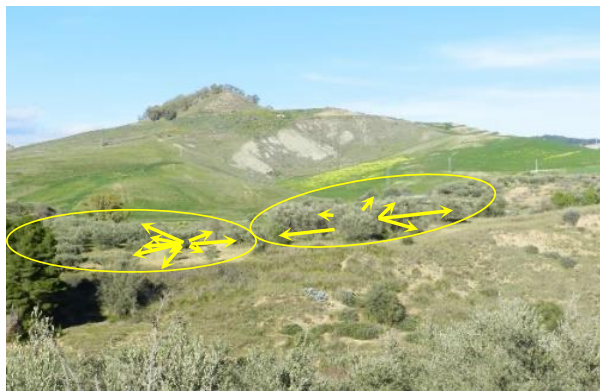

Figure 3b: Spatial context of trees in part of the study site; view from the ground.

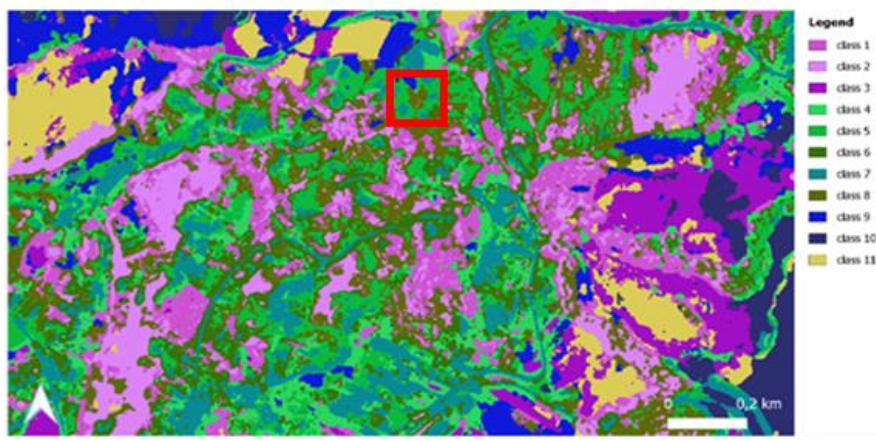

Figure 3c: New composite image showing the spatial objects extracted using the method developed by Malberg et al. (2014).

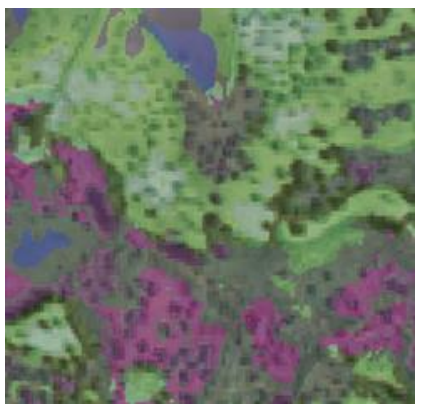

Figure 3d: Olive trees segmented and classified into spatial objects according to their spatial contexts. Section of the study site, view from above. 


\section{Development of ontology, in-field validation and classification of spatial objects}

Seen from above, at first sight the study area appears to be a homogeneous landscape of olive orchards. Nonetheless, the different spatial objects extracted show that each is characterized by a unique contextual configuration of the image elements (pixels), corresponding to unique characteristics resulting from different spatial arrangements. These spatial arrangements are the expression of diverse human land-use strategies over time. The interpretation of these local configurations cannot be done directly from the images and requires expert knowledge of the local farming systems (Wästfelt, 2015).

To proceed with the interpretation of the objects extracted, the authors adopted abductive logic (Couclelis, 2009; Khazraee and Khoo, 2011), associating expert knowledge (Ferrara et al,, 2019) with the low-level information obtained from the image objects by visual interpretation. It was thus possible to perceive these objects, conceptually, as being embedded within an (apparent) hierarchy of spatial complexity. Deconstructing this complexity level by level made it possible to uncover the meanings of the spatial arrangements that these land-use configurations represent.

The authors developed a spatial-relational ontology (Figure 4) which was used to semantically interpret these spatial objects. There followed field validation of the interpretation and the final classification (see Rajbhandari et al., 2017; Argyridis and Argialas, 2019). Methods combining spatial and thematic semantics have only recently started to be developed to address complex geospatial features (Blaschke et al., 2014). A spatial-relational ontology is an ontology that highlights the relational aspects of space (sensu Grauer, 2019; Kokla and Guilbert, 2020) and the human intentions in the use of space. Configurations of space are the expression of human-nature relationships, co-constituting themselves and creating the relational historical process, which unfolds in space, and has primacy over single discrete entities (Ferrara et al., forthcoming).

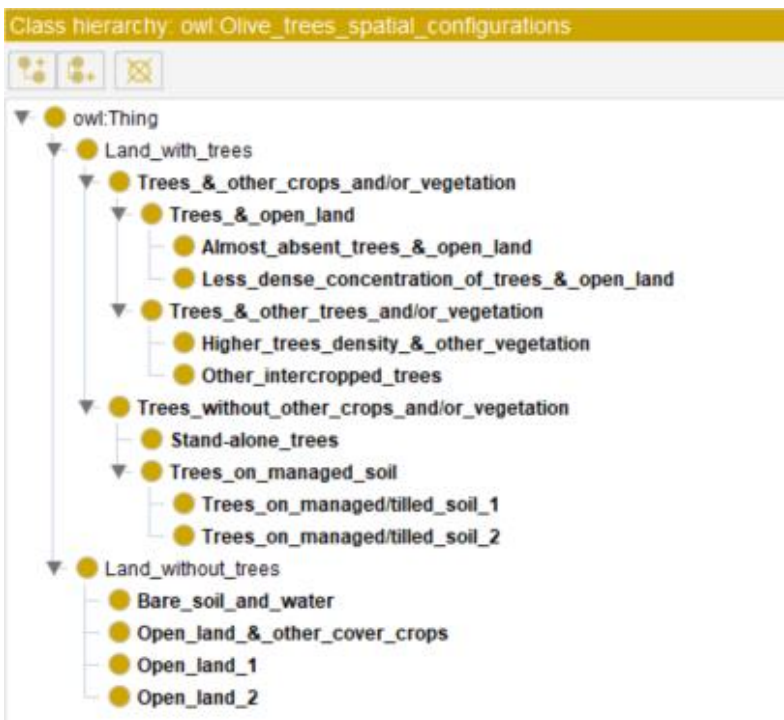

Figure 4:

Spatial-relational ontology developed to interpret semantically the spatial objects extracted as described in the chapter "Development of ontology, in-field validation and classification of spatial objects". 
In the spatial-relational ontology, on the first level of spatial complexity, a conceptual distinction is made according to the presence or absence of trees. The main classes are simply 'Land without trees' and 'Land with trees', which are super-objects in ontological terms (sensu Huang et al., 2017).

The two super-objects are then further classified, on a second level of spatial complexity, according to differences in each spatial arrangement of land-use:

a) Within the super-object 'Land without trees', four different configurations can be distinguished:

'Open land \#1' (open land type 1)

'Open land \#2' (open land type 2)

'Bare soil and water' (bare soil, rocks, water)

'Open land \& other cover crops'

b) Within the super-object 'Land with trees', there are two different spatial configurations:

'Trees \& other crops and/or vegetation'

'Trees without other crops and/ or vegetation'

At a third, deeper, level of spatial complexity, the super-object 'Land with trees' can be further sub-divided.

Within the object 'Trees \& other crops and/or vegetation', a distinction can be made between

- Sub-object 'Trees and open land' (grassland) (trees intercropped with grasslands, pastures, etc.)

and

- Sub-object 'Trees \& other trees and/or vegetation' (trees intercropped with other trees, cover crops and/or in plots where there are other significant vegetation features)

Within the object 'Trees without other crops and/or vegetation', a distinction can be made between

○ Sub-object 'Trees on managed soil' (trees on land which has been heavily worked by removing all vegetation apart from the trees)

and

- Sub-object 'Stand-alone trees' (trees scattered widely, or used as markers, or groups of trees used for fences).

At the final level of spatial complexity extracted, further divisions are made.

Within the object 'Trees \& other crops and/or vegetation',

$\circ$ the sub-object 'Trees and open land' (grassland) is further distinguished according to the density of the trees into:

- 'Less dense concentration of trees and open land'

- 'Almost absent trees and open land'

○ the sub-object 'Trees \& other trees and/or vegetation' is also further distinguished according to tree density into:

- 'Higher tree density \& other vegetation' 
- 'Other intercropped trees'

Within the object 'Trees without other crops and/or vegetation',

○ the sub-object 'Trees on managed soil' is further distinguished into:

- 'Trees on managed/tilled soil \#1' (trees on land which has been heavily worked by removing all other vegetation and cover crops)

- 'Trees on managed/tilled soil \#2' (trees and bare soil, rock, concrete, etc.).

To cross-validate the semantic interpretation of the spatial objects extracted, fieldwork was carried out in the study site from June to November 2020. Three sampling units per class were taken (total: 33 samplings), in order to:

1) explore and confirm the local spatial configuration assigned to each class;

2) explore and confirm the content of each class in terms of vegetation composition and other existing relevant features;

3) collect further complementary data (e.g. size of tree trunks).

The spatial objects extracted from the orthophoto were classified according to the validated ontology; the resulting classes are shown in Figure 6.

\section{Extraction of temporalities}

In the final step of the methodology, the spatial classes extracted as described in chapter "Development of ontology, in-field validation and classification of spatial objects" are used as temporal proxies to determine the different temporalities of the olive cultivation arrangements in the study site.

\section{Spatial classes as temporal proxies}

In the past, olive groves were mostly agro-forestry systems. The logic behind their spatial arrangements was to maximize the use of the empty spaces between the sparsely-planted trees by growing other crops (e.g. vegetables or fruit trees). Originally, local spatial configurations of olives are thought to have been scattered and sparse (Ruhl et al., 2011; Marchetti et al., 2002). Starting from this assumption, the authors referred to this configuration (sparse scattered olive trees) as T1 (time 1).

At a later stage, T2, more 'structured' orchards and groves began to appear, corresponding to intensified/optimized land use: instead of cultivating between widely spaced trees, land users preferred to focus on a single crop (the olive) and intensified its cultivation either by reducing the spaces between trees, or by removing competition from other crops (Ruhl et al., 2011; Barbera and Cullotta, 2016).

These temporal dynamics of land use and their intensification thus have spatial dimensions as well. These are relational in the sense that they are expressions of both cultural/social and natural/ecological processes.

\section{Temporal interpretation, and re-classification of spatial classes as temporalities}

Following these assumptions about changes in olive cultivation over time, the authors developed a temporal interpretation of the spatial classes extracted. The spatial classes were re-classified as temporalities: 
- Within the Class 'Trees \& other crops and/or vegetation', Class 'Trees and open land' is older than Class 'Trees \& other trees and/or vegetation', since more widespread trees implies an older spatial arrangement for planting and land use.

With reference to the final class taxonomy described in chapter "Development of ontology, in-field validation and classification of spatial objects" (see Figure 6), the temporal progression is:

Class 2-1-1 (and relevant subclasses) $=\mathrm{T} 1 \_\mathrm{t} \& \mathrm{v}$ (time $1-$ trees and vegetation) $>$ Class 2-1-2 (and relevant subclasses) $=\mathrm{T} 2$ _t\&v (time $2-$ trees and vegetation) (see Table 1).

- Within the Class 'Trees without other crops and/or vegetation', a temporal distinction is possible at the 4th level of classification:

- Class 'Trees on managed/tilled soil \#1' represents spatial patterns of trees that are older than Class 'Trees on managed/tilled soil \#2' and Class 'Stand-alone trees', because it comprises widely-spaced and scattered trees, and because 'Trees on managed/tilled soil \#2' also incorporates more recent objects, such as bare soil or concrete.

- Class 'Stand-alone trees' comprises trees which are scattered, and trees that in some cases look like borders, markers or fences. Such spatial configurations are probably older when found on worked land, but less old when associated with Class 'Trees on managed/tilled soil \#2' (bare soil, concrete, road, etc.). The authors decided therefore that Class 'Stand alone trees' is less old than Class 'Trees on managed/tilled soil \#1', but older than Class 'Trees on managed/tilled soil \#2'.

The temporal progression is thus: Class 2-2-1-1 $=$ T1_t\&ms (trees and managed soil) $>2-2$ 2-1 = T2_t\&ms $>2-2-1-2=$ T3_t\&ms (Table 2).

Table 1: Temporal progression for Class 'trees \& vegetation' (2-1).

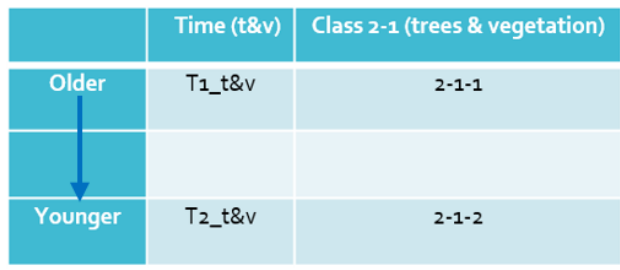

Table 2: Temporal progression for Class 'trees \& managed soil' (2-2).

\begin{tabular}{|c|c|c|}
\hline & Time (t\&ms) & Class 2-2 (trees \& managed soil) \\
\hline Older & T1_t\&ms & $2-2-1-1$ \\
\hline & T2_t\&ms & $2-2-2-1$ \\
\hline & T3_t\&ms & $2-2-1-2$ \\
\hline
\end{tabular}

\section{Results: Unpacked layers of space-time complexity}

Thanks to the methodological approach developed and presented here, the authors were able to unpack the spatial and temporal complexity in the land-use dynamics of an apparently homogeneous area.

Through contextual and spatial-relational analysis, it was possible to extract spatial classes corresponding to different local configurations of olive trees (i.e. specific spatial arrangements of their cultivation, and spatial relationships with other vegetation and manmade features). 
These classes are the expression of geographical contextual configurations, the result of strategies employed by people dwelling in the landscape, and adapting to it for land-use purposes: the classes correspond to different spatial logics in planting olive trees and, above all, increasing degrees of complexity in the spatial arrangements (Figure 5).
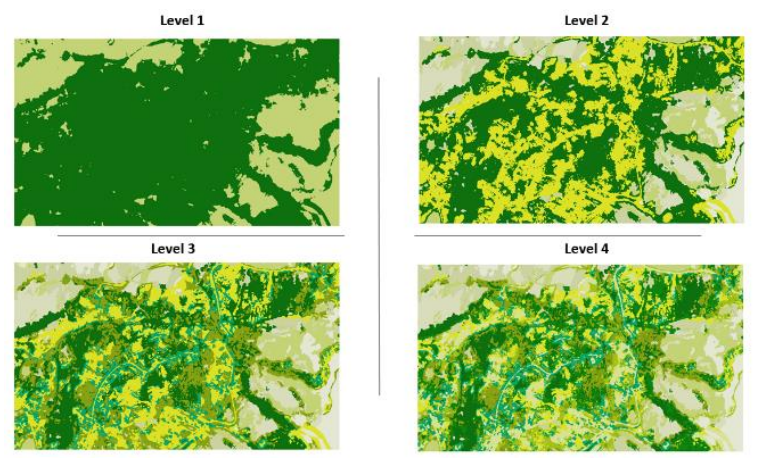

\section{Figure 5:}

Different levels of relational complexity in the spatial arrangements of the landuse configurations extracted using the method devised by Malberg et al. (2014).

Supported by the development of a spatial-relational ontology, a higher level of semantic abstraction was reached in assigning a meaning to these classes, moving from purely geometric and spatial properties to the normative dimension of human land use. After validation in the field, the definitive classification of the spatial patterns extracted was finalized, as shown in Figure 6.

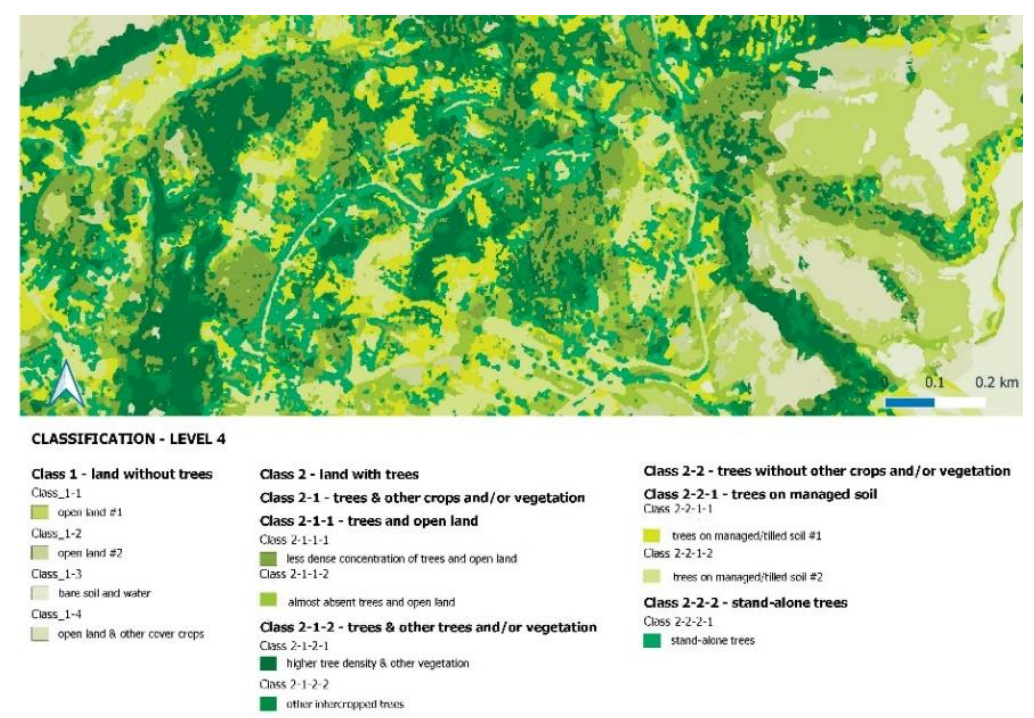

Figure 6: Final classification taxonomy.

In the last step of the approach (see chapter "Extraction of temporalities"), a trans-temporal representation of the geographical patterns of olive trees (Figure 7) was achieved, as the authors were able to extract different temporal dimensions from the local spatial configurations. 


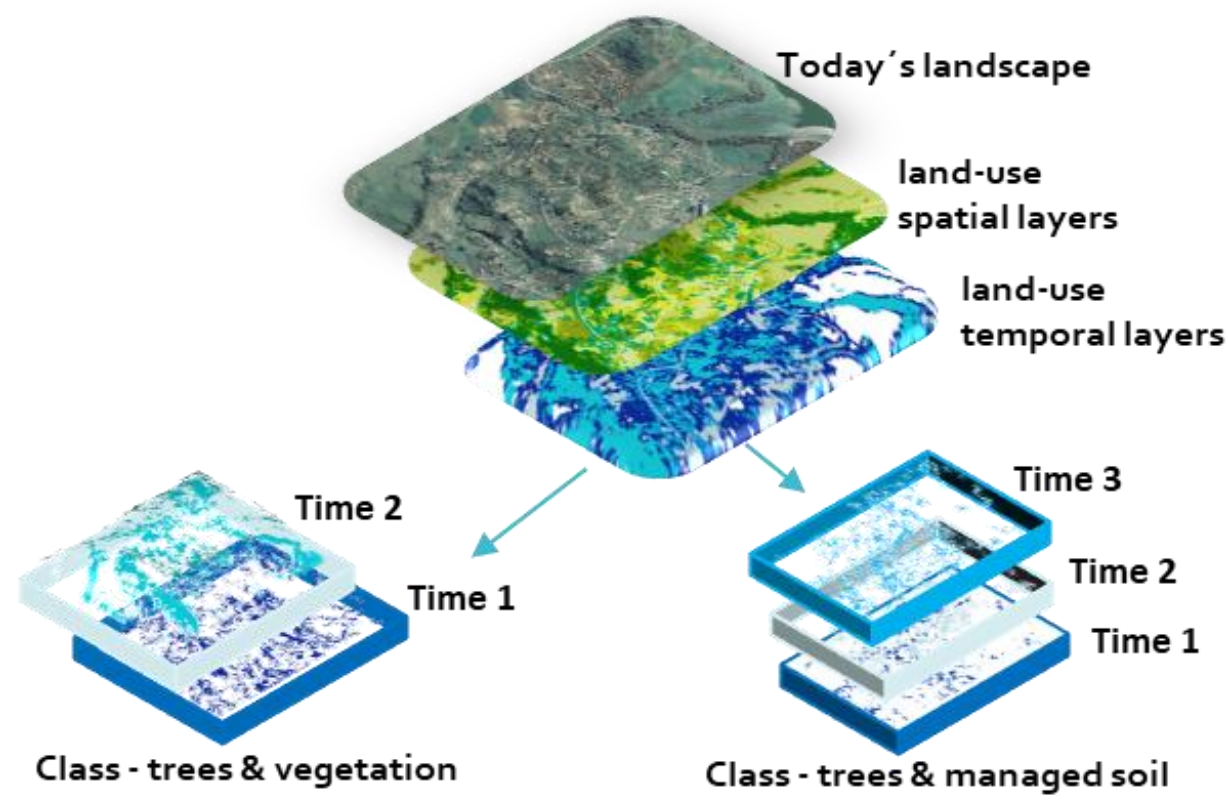

Figure 7: Different temporal dimensions of spatial configurations of olive trees extracted for Class 'trees \& vegetation' and Class 'trees \& managed soil'.

The overall result is very far from traditional land-cover or land-use maps, since here it is possible to visualize local contextual information corresponding to different human reasoning over time, which resulted in the different spatial configurations of the land-use practices.

\section{Concluding discussion}

Results obtained from the application of the approach presented here show that, by moving from the different reflectance levels of a remotely sensed image to meaningful categories of land use as composite, socially determined, spatio-temporal concepts (Wästfelt, 2015), it is possible to unpack the specific spatial configurations of land use during different periods.

By using evidence of biocultural heritage present in today's landscape as a 'bioindicator' of past land-use dynamics, and integrating methods from several different disciplines (historical ecology, archaeology, GIScience, philosophy, remote sensing), the authors developed a crossdisciplinary approach which is useful to inform analysis in deep time. Techniques for the extraction of spatial-relational data from remotely sensed images had not before been used to track land-use dynamics over the long term (i.e. over centuries or millennia) (Agapiou, 2020; Davis, 2019). Nor had the identification of contextual relations been used before to semantically uncover land-use categories and formally define them as conceptual spaces (Ahlqvist et al., 2012) correlated to different time periods. The methodology presented here may therefore be promising for transferability to, and applications in, human sciences and other disciplines studying landscape and land-use dynamics. 
Of course, ground validation data must always substantiate the results from spatial analysis. One limitation of the work presented here is the lack of validation of the final temporal classification, which would require evidence provided by alternative dating methods (e.g. dendrochronology, or isotope analysis of plant and soil remains). Moreover, although described in a semi-formal notation, the spatial-relational ontology developed in this paper is still missing a true formalization according to the standards (e.g. OWL). The reason for this lies in the difficulties of developing formal ontologies when looking at landscape features in the context of human sciences and social interactions (Khazraee and Khoo, 2011; Janowicz et al., 2012). Nonetheless, perspectives found in the human sciences, such as historical ecology, can be used to achieve deeper interpretations of remotely sensed datasets. At the same time, advanced spatial analysis techniques may help as a further interpretative and directional tool. The integration of these different approaches could open up a dialogue across disciplinary boundaries and advance the scientific analysis of biocultural heritage.

\section{Acknowledgements}

This work was supported by Vetenskapsrådet (Swedish Research Council) as part of the research project 'The Biocultural Heritage of Sicilian Olive Trees', grant number 2020-02625.

The authors would like to thank the anonymous peer reviewers for their very helpful comments on this manuscript. Any errors are the responsibility of the authors.

\section{References}

Agapiou, A. (2020). Evaluation of Landsat 8 OLI/TIRS Level-2 and Sentinel 2 Level-1C Fusion Techniques Intended for Image Segmentation of Archaeological Landscapes and Proxies. Remote Sensing, 12, 579 .

Ahlqvist, O., Wästfelt, A., Nielsen, M. (2012). Formalized interpretation of compound land use objects - Mapping historical summer farms from a single satellite image. Journal of Land Use Science, 7(1), 89-107.

Argyridis, A., Argialas, D. (2019). Fuzzy ontology-based foreshore identification from digital terrain models and very high-resolution airborne imagery through GEOBIA multi-scale analysis. International Journal of Geographical Information Science, 33:11, 2153-2169.

Barbera, G., Cullotta, S. (2016). The Traditional Mediterranean Polycultural Landscape as Cultural Heritage: Its Origin and Historical Importance, Its Agro-Silvo-Pastoral Complexity and the Necessity for Its Identification and Inventory (Part I, Chapter 1). In M. Agnoletti \& F. Emanueli (Eds.), Biocultural Diversity in Europe: Springer.

Barthel, S., Crumley, C.L., Svedin, U. (2013). Biocultural refugia: combating the erosion of diversity in landscapes of food production. Ecology and Society 18(4), Article 71.

Blaschke, T. (2010). Object based image analysis for remote sensing. J. Photogramm. Remote Sens, $50(1), 2-16$.

Blaschke, T., Hay, G.J., Kelly, M., Lang, S., Hofmann, P., et al. (2014). Geographic Object-based Image Analysis: A new paradigm in Remote Sensing and Geographic Information Science. J. Photogramm. Remote Sens, 87, 180-191.

Calafiore, A., Boella, G., Borgo, S., Guarino, N. (2017). Urban Artefacts and Their Social Roles: Towards an Ontology of Social Practices. In E. Clementini, M. Donnelly, M. Yuan, C. Kray, P. 
Fogliaroni \& A. Ballatore (Eds.) 13th International Conference on Spatial Information Theory (COSIT 2017), Article No. 6; pp. 6:1-6:13. Leibniz International Proceedings in Informatics. Schloss Dagstuhl - Leibniz-Zentrum für Informatik, Dagstuhl Publishing.

Couclelis, H. (2009). The Abduction of Geographic Information Science: Transporting Spatial Reasoning to the Realm of Purpose and Design (Part VII, Chapter 1). In K.S. Hornsby, C. Claramunt, M. Denis \& G. Ligozat (Eds.), Spatial Information Theory. COSIT 2009. Lecture Notes in Computer Science, vol 5756: Springer.

Crumley, C. (2019). New Paths into the Anthropocene: Applying Historical Ecologies to the Human Future (Part I, Chapter 1). In C. Isendahl \& D. Stump (Eds.), The Oxford Handbook of Historical Ecology and Applied Archaeology: Oxford University Press.

Davis, D.S. (2019). Object-based image analysis: a review of developments and future directions of automated feature detection in landscape archaeology. Archaeological Prospection, 26: 155- 163.

Ferrara, V., Ekblom, A., Wästfelt, A. (2019). Biocultural heritage in Sicilian olive groves; the importance of heterogeneous landscapes over the long term. In M.I. Goldstein \& D.A. DellaSala (Eds.). 2020. Encyclopedia of the World's Biomes, Elsevier.

Ferrara, V., Wästfelt, A. Ekblom, A. (forthcoming). From landscape as heritage to biocultural heritage in a landscape. The ecological and cultural legacy of millennial land use practices for future natures. In G.Pettenati (Ed). 2021. Landscape as heritage: critical perspectives. London, Routledge.

Gobbi, S., Ciolli, M., La Porta, N., Rocchini, D., Tattoni, C., Zatelli, P. (2019). New Tools for the Classification and Filtering of Historical Maps. ISPRS Int. J. Geo-Inf., 8, 455.

Grauer, K.C. (2019). Active environments: Relational ontologies of landscape at the ancient Maya city of Aventura, Belize. Journal of Social Archaeology, 20(1), 74-94.

Gurney, M.C., Townshend, J.R.G. (1983). The use of contextual information in the classification of remote sensed data. Photogrammetric Engineering and Remote Sensing, 49(1), 55-64.

Hay, G.J., Castilla, G. (2008). Geographic Object-Based Image Analysis (GEOBIA): a new name for a new discipline. In: T. Blaschke, S. Lang, G. Hay (Eds.), Object-Based Image Analysis. Springer, Heidelberg, Berlin, New York, pp. 75-89.

Huang, H., Chen, J., Li, Z., Gong, F., Chen, N. (2017). Ontology-Guided Image Interpretation for GEOBIA of High Spatial Resolution Remote Sense Imagery: A Coastal Area Case Study. ISPRS Int. J. Geo-Inf., 6, 105.

Janowicz, K., Scheider, S., Pehle, T., Hart, G. (2012). Geospatial semantics and linked spatiotemporal data - Past, present, and future. Semantic Web 3, 321-332. IOS Press.

Khazraee, E., Khoo, M. (2011). Practice-Based Ontologies: A New Approach to Address the Challenges of Ontology and Knowledge Representation in History and Archaeology. In E. GarcíaBarriocanal, Z. Cebeci, M.C. Okur, A. Öztürk (Eds.) Metadata and Semantic Research. MTSR 2011. Communications in Computer and Information Science, vol 240. Springer, Berlin, Heidelberg.

Kokla, M., Guilbert, E. (2020). A Review of Geospatial Semantic Information Modeling and Elicitation Approaches. ISPRS Int. J. Geo-Inf., 9, 146.

Lambers, K., Traviglia, A. (2016). Automated detection in remote sensing archaeology: a reading list. AARGnews 53, 25-29.

Lang, S., Hay, G.J., Baraldi, A., Tiede, D., Blaschke, T. (2019). GEOBIA Achievements and Spatial Opportunities in the Era of Big Earth Observation Data. ISPRS Int. J. Geo-Inf., 8, 474.

Lasaponara, R., Masini, N. (2014). Beyond modern landscape features: New insights in the archaeological area of Tiwanaku in Bolivia from satellite data. International Journal of Applied Earth Observation and Geoinformation, 26: 464-471.

Lombardo, V., Damiano, R., Karatas, T., Mattutino, C. (2020). Linking Ontological Classes and Archaeological Forms. In: J. Z. Pan et al. (Eds.) ISWC 2020, LNCS 12507, pp. 700-715, Springer Nature Switzerland. 
Luo, L., Wang, X., Guo, H., Lasaponara, R., Zong, X., et al. (2019). Airborne and spaceborne remote sensing for archaeological and cultural heritage applications: A review of the century (1907-2017). Remote Sensing of Environment, 232, 111280.

Magnini, L., Bettineschi, C. (2019). Theory and practice for an object-based approach in archaeological remote sensing. Journal of Archaeological Science, 107, 10-22.

Malmberg, B., Nielsen, M., Wästfelt, A. (2014). Method for Performing Automatic Classification of Image Information. Patent No. 8,781,216. Washington, DC: U.S. Patent and Trademark Office.

Manzano, S., Julier, A.C.M., Dirk, C.J., Razafimanantsoa, A.H.I., Samuels, I., et al. (2020). Using the past to manage the future: the role of palaeoecological and long-term data in ecological restoration. Restor Ecol, 28: 1335-1342.

Marchetti, M., La Mantia, T., Messana, G., Barbera, G. (2002). Il significato dei popolamenti arborei ed arbustivi fuori foresta nel paesaggio agrario e la loro dinamica evolutiva in due aree campione della Sicilia. L'Italia Forestale e Montana 57(4), 369-389.

Mathian, H., Sanders, L. (2015). Spatio-temporal approaches: geographic objects and change process. London; John Wiley \& Sons.

Pricope, N.G., Mapes, K.L., K.D. Woodward (2019). Remote Sensing of Human-Environment Interactions in Global Change Research: A Review of Advances, Challenges and Future Directions. Remote Sens., 11, 2783.

Rajbhandari, S., Aryal, J., Osborn, J., Musk, R., Lucieer, A. (2017). Benchmarking the Applicability of Ontology in Geographic Object-Based Image Analysis. ISPRS Int. J. Geo-Inf., 6, 386.

Ray, C., Fernández-Götz, M. (2019). Historical Ecologies, Heterarchies and Transtemporal Landscapes. London: Routledge.

Ruhl, J., Caruso, T., Giucastro, M., La Mantia, T. (2011). Olive agroforestry systems in Sicily: Cultivated typologies and secondary succession processes after abandonment. Plant Biosystems, 145(1), 120-130.

Schuurman, N. (2006). Formalization Matters: Critical GIS and Ontology Research. Annals of the Association of American Geographers, 96: 726-739.

Sevara, C., Pregesbauer, M., Doneus, M., Verhoeven, G., Trinks, I. (2016). Pixel versus object — A comparison of strategies for the semi-automated mapping of archaeological features using airborne laser scanning data. Journal of Archaeological Science: Reports, 5: 485-498.

Tapete, D. (2018). Remote Sensing and Geosciences for Archaeology. Geosciences, 8, 41.

Traviglia, A., Torsello, A. (2017). Landscape Pattern Detection in Archaeological Remote Sensing. Geosciences, 7(4), 128.

Wästfelt. A. (2015). Reclaiming Position: Using Local Context to Visualise Interpretations of Satellite Images in Humanities and Social Science. Journal of Art History, 84, 2, 108-122.

Wästfelt, A. (2021). Landscape as filter - farm adaptation to changing contexts. Journal of Land Use Science, 1-17. 